\title{
Research on the Quality and Promotion Path of Master Degree Thesis
}

\author{
Zhixin Zhang ${ }^{1}$, Qibiao Zhang ${ }^{2}$ and Xiaobing Yang, \\ ${ }^{1}$ School of Economics, Shandong University of Technology \\ Zibo, China \\ Email: beiji2002 [AT] 126.com \\ ${ }^{2}$ Guilin tourism college \\ Guilin, China \\ ${ }^{3}$ Department of Teaching, Shandong University of Technology \\ Zibo, China \\ *Corresponding author's email: licheng0633 [AT] 126.com
}

\begin{abstract}
The quality of dissertations is the basic core of the development of professional degree postgraduate education. With the transformation of economic development mode and the steady progress of the construction of an innovative country, the demand for professional degree postgraduates in economic and social development has increased significantly. The result is that the number of significant growth and the quality is difficult to guarantee. The most prominent is that the quality of professional degree postgraduates represented by dissertations has declined to varying degrees. Through on-the-spot investigation, this paper concludes that there are four prominent problems in the quality of professional degree master 's degree thesis: the topic is not suitable, the research is not deep enough, the content is not innovative and the writing is not standardized. Therefore, it is possible to achieve the goal of improving the quality of professional degree master's degree papers only by strictly controlling the topic selection, adhering to the problem research orientation and implementing the basic attributes of innovation.
\end{abstract}

Keywords - Dissertations, master of professional degree, graduate training quality

\section{INTRODUCTION}

The quality of professional degree master 's training has aroused widespread concern in the community. Since the first admission of MBA master 's degree in 1992, the cultivation of professional master 's degree has not only formed a complete degree award system from bachelor 's degree, master 's degree to doctor 's degree, but also achieved innovative development in its training objectives, curriculum setting and training mode. Although professional degree postgraduates are 'imported ', they have achieved rapid development once introduced. According to the data, the number of master 's degree candidates in China has reached 439000 in 2018, nearly 100,000 more than academic postgraduates, accounting for $57.6 \%$. The fundamental reason for the rapid development of professional degree postgraduates is that their talent training objectives adapt to the demand for high-level specialized applied talents in China 's economic and social development. In addition to knowledge innovation and inheritance, education should also cultivate qualified talents for economic and social development.In the Introduction section, present clearly and briefly the problem investigated, with relevant references. The main results should be enunciated. After the reform and opening up, especially in the $21 \mathrm{st}$ century, with the transformation of the mode of economic development and the steady progress of the construction of an innovative country, economic and social development puts forward higher requirements for the cultivation of professional degree postgraduates, that is, no longer just ' focus on cultivating research talents with original spirit and ability , ${ }^{[1]}$ but pay more attention to cultivating applied talents with specialized knowledge and skills. Obviously, the cultivation of professional degree postgraduates can not keep up with the rapid development of professional degree postgraduates themselves. At present, there are not only a series of problems such as ' lack of practical class hours, ${ }^{[2]}$ convergence of training mode ', insufficient tutor guidance, and not prominent application characteristics ', but also a series of problems such as ' no obvious distinction between curriculum, teaching and academic postgraduate training of professional degree postgraduates.${ }^{[3]}$ Under the background of its rapid development, the quality of professional degree training has naturally become a hot spot of social concern. 


\section{LITERATURE REVIEW}

The quality of dissertation is the final embodiment of the training quality of professional degree master. Although the professional degree master 's training objectives have professional orientation, the training mode has ' industryuniversity-research ' cooperation, the training process has engineering practice and the training content has professional domain, ${ }^{[4]}$ this does not mean that the importance of dissertations in professional degree training can be denied. Professional degree master' $s$ thesis is not only the ability of students to analyze and solve practical problems with the theories and knowledge they have learned, but also a comprehensive test of the training effect of students after the training process. Dissertation is a comprehensive test of postgraduate training, which is different from other training links. Whether it is course or practice, it is only to cultivate students ' knowledge or ability in a certain aspect. Dissertations are different. It is not only necessary to focus on the theme of the paper required by the professional field, on the basis of full investigation and demonstration, and use what you have learned to do a scientific analysis of the research topic, so as to achieve a logical explanation or explanation of the selected topic from the two levels of theory and practice, which has reached the purpose of knowing it and knowing why it is. However, there are many problems in master 's degree thesis, such as ' insufficient theoretical depth ${ }^{[5]}$, simple repetition of previous labor results ${ }^{[6]}$, and lack of meaningful results. ' As an example of medical graduate papers with the most distinctive development of professional degree masters, it is concluded that ' most of the medical graduate paper writing is often out of track with clinical practice, the overall quality of dissertations is not connected, duplication, low level, no practical application significance, the most prominent problem is lack of innovation. ${ }^{[7]}$ In fact, the neglect of dissertations and the lack of investment time are the important reasons for the poor quality of dissertations of professional degree postgraduates. However, at present, there are 11 typical problems in professional master ' $s$ degree papers, such as deviation of topic selection, anomie of literature review, fuzzy core concepts, deviation of research topics, inaccurate countermeasures and suggestions, chaotic logical thinking, insufficient research process, improper research methods, random demonstration materials, lack of professional knowledge and serious plagiarism. Overall, although the quality of professional degree training is the result of a variety of factors, the quality of dissertations is the most important embodiment, the core part and the most important grasp of the quality of professional degree postgraduate training. In order to improve the quality of professional degree master ' $\mathrm{s}$ degree papers, we must understand what forms of the quality of degree papers, in order to ' suit the remedy to the case ', it is possible to ' cure the disease ', otherwise it may be around the 'quality of degree papers '.

\section{THE MANIFESTATION OF THE QUALITY OF PROFESSIONAL DEGREE MASTER ' S DEGREE THESIS}

What are the forms of professional degree master 's degree thesis quality ? The quality of professional degree thesis is the most important starting point for the development of professional degree master ' $\mathrm{s}$ education, but there is no consensus on which aspects to improve the quality of professional degree thesis. For example, ' there is no relatively clear and consistent criteria for the selection of topics, writing forms, evaluation criteria, writing norms and innovation of professional master' $s$ degree papers ${ }^{[8]}$. However, the evaluation criteria only guide the professional degree master degree thesis quality trend, not the thesis quality itself. Therefore, we should start from the analysis of professional degree papers to find out the key factors that can best reflect the quality of professional degree papers, so as to find out the path to improve the quality of professional degree papers..

\subsection{Unqualified topics}

The topic selection is the basic guarantee for the quality of dissertations. The topic selection is the most basic and key step in the research work. Choosing a suitable topic is the key to the success of the thesis. Although professional degree master' $s$ thesis is different from academic degree in terms of innovation and theoretical requirements, it should also be studied based on the problems that need to be solved in the field of professional degree. For example, the topic of Business Administration ( MBA ) papers should be ' around non-profit companies or business practices in production management applications or practical issues '. The topic selection of agricultural master 's thesis should focus on the application subjects and practical problems of scientific and technological innovation, technological innovation, popularization and application and management in agricultural production practice or rural development practice. However, through the investigation on the dissertations of Master of Arts in 12 universities in Beijing, Shandong, Inner Mongolia and Hubei, it is found that in the process of cultivating Master of Arts, although the National Professional Degree Teaching and Instruction Commission has put forward specific requirements for the topic selection of the papers, many training units of Master of Arts are either based on literature or theoretical assumptions under the inertia of academic degree thinking, and lack practicability without deepening into the production practice or career development needs of enterprises. Either in a narrow range, do some simple investigation and study, and then write a seemingly standardized thesis, in fact, due to the small scope of topics, typical and representative is not strong, and the lack of universality and regularity. Taking Master of Agriculture as an example, on the one hand, ' rural tourism ', ' farmers ' income increase ', ' rural amount ',' ' farmer cooperatives ' and so on Thematic words frequently appear in the topic selection over the years, and there is little difference between the topics of the superior and subordinate papers, lacking new ideas. On the other hand, ' $\times$ county ( or district ) ', ' $\times$ town ( street ) , and even ' $\times$ village ( company ) ' are 
selected as the scope of this paper. Although it can be seen from small to large, if the sample size is too small, the popularization and application value of our research results is worth pondering. The same problem also exists in the topic selection of professional degree papers in other liberal arts disciplines.

\subsection{Insufficient research}

Analytical research is the key core of dissertation quality. Dissertation is to find problems, analyze problems, and then to solve problems, which is the general principle of writing papers. It is important to find out the problems, that is, the topic selection of the paper. However, if the problems cannot be well analyzed and the scientific research methods cannot be used to study the problems in detail, how can reasonable and effective research results be obtained. This is equally important for professional degree postgraduate papers. Although our professional degree postgraduate papers do not have key requirements in knowledge innovation, even the application problems in production practice must be found out to provide guidance and reference for production practice. We must correct the one-sided understanding of professional degree master' $s$ thesis. ${ }^{[9]}$ It should be said that since the introduction of professional degree postgraduates into China ' s postgraduate training system, there is a widespread ' professional degree applied high-level talents ' in the quality requirements of academic papers, so the quality of their academic papers cannot be required so high '. What 's more, ' professional degree postgraduates need not write any academic papers as long as they meet the quality and ability required by their profession. The quality of dissertations is the most important indicator of postgraduate training. Even professional degree postgraduates cannot ignore dissertations and their quality requirements on the grounds of application and professionalism, which is also the most fundamental difference from vocational education. However, from the investigation and study, it is known that the professional degree master' s papers are generally " not deeply analyzed". Most of the papers are simply stacked with some materials, which are satisfied with the introduction of concepts and the listing of the status quo. There is a lack of in-depth analysis of research topics, and there is little use of scientific research methods to make detailed research on the research objects. The papers are only the records of flow accounts, and lack of academic opinions and rational analysis of research results, ${ }^{[10]}$ which cannot reflect the level and ability of professional degree master' s papers.

\subsection{No innovation in content}

Content innovation is the essential requirement of dissertation quality. Innovation is the most important difference between dissertations and other articles. Although different types of dissertations have different contents, degrees and requirements of innovation, the pursuit of innovation is the most important indicator of the quality of all dissertations. At present, the research methods of professional degree master 's thesis are simple and convergent, and the problems are lack of necessary analysis and research. The opinions or conclusions are superficial, and most of them do not meet the basic requirements of innovation. Through the investigation, it is found that most of the professional degree master' $\mathrm{s}$ papers of humanities and social sciences are directly from the current situation to the problem, and there is no necessary research method to obtain the problem. The " problems " obtained are basically " peripheral " problems such as imperfect system, unreasonable resource allocation, and insufficient attention, which do not go deep into the real problems facing the research topic. The result is that the research content is plain and not operational. ${ }^{[11]}$ Therefore, it is not difficult to draw the conclusion that there are no new ideas and meaningful results in the innovation of postgraduate dissertations. The innovation of dissertations is not easy, which can reflect the training quality of degree holders. Although professional degree master 's degree thesis does not require theoretical innovation or knowledge innovation, it still requires unique insights from research methods, research perspectives, or research perspectives and conclusions. 'What are so many new questions worth studying? Does a professional master ' $\mathrm{s}$ thesis use so much innovation ? This is the majority of views on the 'innovation ' of master ' $s$ degree thesis in the process of research. It is under the influence of this idea that professional degree graduates do not attach importance to the innovation of dissertations, thus affecting the quality improvement of their dissertations. In fact, if professional degree master students realize that innovation is the essential requirement of degree papers from the perspective of ideology, take part in the production ( social ) practice of not less than six months with research questions, deeply analyze the reality of the research topic, use scientific research methods to raise the perceived problems to the knowledge level, or put forward their own new opinions or solutions to the problems explored, these should all meet the basic requirements of degree paper innovation.

\subsection{Writing is not standard enough}

The paper specification is the external manifestation of the quality of dissertations. Normativeness is the basic requirement for the quality of dissertations, which not only reflects the writing attitude of dissertation writers, but also reflects their academic literacy. Professional degree master' s degree thesis can be either investigation report, problem diagnosis, practice report, application problem research and other categories, but no matter which type must be carried out in accordance with the existing paradigm, otherwise it will fail to meet the requirements of the quality of the degree thesis. In recent years, with the expansion of the enrollment scale of professional degree postgraduates, especially the deviation of understanding of dissertations, both instructors and students themselves have relaxed requirements for dissertations. The most intuitive manifestation is that the normative requirements of professional degree dissertations are significantly lower than academic degrees. For example, ' professional degree master thesis can not be too high ', ' Oh, 
this is professional degree master thesis... ' et al. are often emphasized in the paper. In fact, as long as the degree thesis must conform to academic norms, although different types of degree thesis focus on different. Professional degree thesis normative, first is the normative logic. Both thematic studies and survey reports must follow certain logical thinking. For example, the investigation report, must start from the purpose of the investigation, select the survey object to meet the requirements, select the appropriate survey method, and through the investigation process organization and management, the survey data, data and other collation and analysis, draw the conclusion of the application value. What ' s more, the whole system of the investigation report should also be linked, echo each other, and have logic, rather than independent ' and ' death does not communicate'. The second is language expression norms. Dissertations express a certain ideological point of view through the language used, which is different from work reports, news reports and other styles. In the writing of professional degree papers, they do not pursue gorgeous use professional vocabulary, precise and simple words to express clear views. From the current reality, ' colloquial, journal ' is a more common problem in professional degree master thesis. And the format specification. The format specification of academic papers should not only be beautiful, but also reflect the most basic academic literacy. Although the specific requirements of each school slightly different, but basically follow the ' two lines in front of the paragraph, the name of the picture in the bottom table above, the formula needs mathematical compiler ' and other writing habits. However, master 's degree students should have known this basic academic norm. However, there will be more or less format inconsistency problems when they read their dissertations at random, and some even the most basic beauty is difficult to achieve.

\section{THE PROMOTION PATH OF MASTER DEGREE THESIS}

Dissertation is the most concentrated expression of professional degree graduate training quality. Professional degree graduate education has experienced more than 20 years of development, especially since 2011, in the pursuit of ' extension development but also pay attention to its ' connotative ' development ${ }^{[12]}$, which improve the quality of thesis is not only the inevitable development, but also the most concentrated embodiment of training quality. How to improve the quality of dissertations? Experts and scholars have conducted extensive discussions, but no consensus has been reached. So, the quality of professional degree master ' $\mathrm{s}$ degree thesis, is ' to highlight the characteristics and laws of professional degree graduate education, improve the evaluation system ${ }^{[4]}$, or ' from all aspects of the training process, build the government, universities, enterprises, tutors, graduate students multi-subject, management system, training mode, evaluation standard diversification of the continuous development and change of the security system ${ }^{[13]}$. We believe that the quality of dissertations is the result of multiple factors, which is closely related to the attention paid by instructors, students, employers and other sectors of society. However, in the short term, the improvement of professional degree master 's thesis quality is mainly from the following aspects :

\subsection{Strictly select the topic of the paper}

The topic selection is a key step in the quality of dissertations. The topic selection of dissertations should not only meet the requirements of professional fields, but also reflect the value of research topics. Therefore, in the cultivation of professional degree postgraduates, the topic selection of dissertations is very important. Therefore, according to the professional degree personnel training goal is ' professional, applied ' requirements, attaches great importance to professional degree graduate thesis topics. First of all, through the practice course, enterprise practice and production practice and other teaching links, enhance professional degree graduate students to understand the professional field to be solved ' research topic ' opportunity. In addition to a small number of professional degree master students have the corresponding professional background, most graduate students choose to continue to study on the basis of undergraduate graduation. If there is no above teaching link design or implementation is not in place, this part of the graduate students can only be based on literature, previous students and subjective assumptions. Secondly, give full play to the role of enterprise tutors and industry experts in the topic selection of professional degree master ' $\mathrm{s}$ thesis, not only to play the effectiveness of this part of the power in the teaching link, but also through expert lectures, academic salons and other ways to bring the problems to be solved in industrial development and production practice to these young students. This can greatly reduce the professional degree master ' $\mathrm{s}$ thesis topics professional inadaptability, targeted problems and practical needs. In addition, various channels such as industry associations, industrial development forums and school alumni associations are used to solicit topics for graduation thesis from professional fields. The topic selection of professional degree thesis should be based on the practical needs of industrial development, which is to solve the problems encountered in production practice. The most clear grasp of these information should be the professional degree of industry experts, industry association members and other professionals, but master degree students, even their instructors are not necessarily familiar. Therefore, through the above activities, it is very important to enhance the dialogue and communication between professional degree master students and industry related personnel.

\subsection{Insisting on Problem Research Orientation}

Analytical research is the basic requirement of thesis quality. The quality of dissertations is directly determined by the depth of the research. As a dissertation, if there is no reasonable analysis and in-depth study of the research topic, it can not be regarded as a high-quality dissertation, and professional degree dissertation is no exception. This not only needs to change people ' $\mathrm{s}$ understanding of professional degree papers, but also needs to clarify the proper position of ' 
analytical research ' in professional degree master ' s papers. First, we must realize that ' analytical research ' is the soul of professional degree thesis. Before writing degree papers, professional degree postgraduates should understand that the so-called papers are to use scientific research methods to analyze and study the problems existing in the " research theme, " so as to obtain convincing research conclusions. Although there are many forms of professional degree papers, they all need to analyze and study the research objects, so as to obtain universal conclusions or laws. Secondly, through the centralized guidance of thesis design and research methods, let each professional degree master master master master master the basic logic of thesis and master the necessary research methods, so as to change the simple description of the research topic, especially the lack of objective and fair ' analysis and research ' on the problems existing in the research topic. This is not conducive to revealing the phenomenon or problems, more importantly, can not convince the reader through discourse. Also, increase the proportion of ' analytical research ' in dissertation quality evaluation. The evaluation index is an important indicator of the quality of dissertations. What kind of evaluation index of the quality of dissertations will have what level of dissertations. Therefore, professional degree training units should not only take ' analytical research ' as an evaluation index, but also adjust its proportion as the most important part of paper quality evaluation.

\subsection{Implementing the Basic Requirements of Innovation}

Insisting on innovation is the basic attribute of dissertation quality. Innovation is the main aspect of dissertations different from general articles. General articles can be summarized, narrative and so on, but academic papers should focus more on innovation than simply narration. The lack of innovation is the most prominent and concentrated problem in the quality of professional degree master ' $\mathrm{s}$ thesis in China. We believe that to enhance the innovation of master ' $\mathrm{s}$ degree thesis, first of all, to understand what is the innovation of degree thesis ? The innovation of dissertations is neither ' fabrication ' nor ' curiosity '. The innovation is mainly based on the discussion of the research methods, research perspectives, research conclusions, and even solutions. Secondly, why should dissertations pay attention to innovation ? The reason why dissertations attach importance to innovation is because of their mission, either to innovate knowledge, or to explore the law, at least to explore the problem and find solutions. Professional degree master ' $\mathrm{s}$ degree thesis without innovation, knowledge simple repetition, there is little value. Also, how to innovate dissertations ? The innovation of professional degree thesis should play a comprehensive role of multiple subjects. Professional degree training units should not only cultivate innovative literacy from the design of teaching content, but also actively create an innovative environment through innovative forums, selection and sharing of excellent papers. At the same time, the enthusiasm and initiative of graduate students and instructors should be exerted. In the innovation of dissertations, although the main body is the graduate student himself, the tutor should play a leading role. In the planning and writing of dissertations, postgraduates should be actively guided to think about research topics, develop research ideas and use research methods, so as to stimulate postgraduates to analyze problems in depth and put forward their own insights.

\subsection{Strictly of dissertations}

The paper specification is an important part of the quality of dissertations. Professional degree master degree thesis quality is not high, the most intuitive feeling is the normative degree thesis, including thesis logic specification, language specification and format specification. The degree thesis is to follow certain logical norms. Masters of professional degree must have the consciousness of "problem " and follow the basic idea of " discovering, analyzing and solving problems ". At the same time, there is a logical correlation between each part of the degree paper. Whether in the framework design of the paper or in the process of writing the paper, we must discuss the " theme " according to a certain logic, rather than being isolated from each other and difficult to become a whole. Secondly, academic papers are different from other articles such as news reports and summary reports. Their language does not require exaggerated or gorgeous words, and it can be expressed in simple and accurate normative language. However, it can not be colloquialized '. After all, it is in writing academic papers, so it is the most basic to use the ' academic ' language which is suitable for written expression. At the same time, it must be strict in academic languages such as professional terms and special nouns, and can not be changed arbitrarily. Of course, you can 't create some so-called ' terminology ' that doesn 't meet the requirements of professional norms for ' attracting the eye. Therefore, teachers should not only strengthen the education of academic language norms of professional degree postgraduates, but also increase the guidance of language norms in the process of paper review. The format specification can also reflect the quality of professional degree papers. Training units and instructors should not only strengthen the guidance of the format specification of dissertations in the training process, clarify the number size, line spacing, chart format and other contents of dissertations, but also strengthen the awareness of format specification for professional degree graduates through the training of format specification. Especially in the process of graduation thesis writing, not only through the template, demonstration and other ways to strengthen the guidance of the format specification of degree thesis, but also to be corrected in time that does not conform to the format specification, which also includes correcting students ' attitude to engage in the work of degree thesis.

In short, improving the quality of dissertations is an inevitable choice for China ' $\mathrm{s}$ professional degree master education to realize the transformation from ' extension ' to ' connotation '. Although the quality of dissertations of professional degree postgraduates is affected by many factors such as the quality of students, the training mode and the 
evaluation of dissertations, from the current stage of development, the improvement of the quality of dissertations of professional degree postgraduates should not only fully realize that the quality of dissertations is an important manifestation of the training quality of professional degree postgraduates, but also pay attention to the quality of dissertations of professional degree postgraduates by training units, employers and all sectors of society. More importantly, we should attach importance to the topic selection, focus on analysis and research, highlight the innovation of papers and strict academic norms to promote the application and pertinence of master degree thesis, and strive to improve the level and ability of master degree students to solve practical problems, so as to realize the development goal of cultivating high-level applied talents for the professional field.

\section{REFERENCES}

[1] Liu Huajun and Li Xianyun. The Cultivation Attributes and Ways of Professional Degree Postgraduates - Taking the Electrical Engineering Field of Nanjing University of Engineering as an Example [J]. Degree and Postgraduate Education, 2014 (4) : 16-21.

[2] Zhang Fan, Ye Gongyin, and Yuan Xixian. Investigation and analysis of the status quo of the cultivation of full-time agricultural extension professional degree postgraduates - taking Zhejiang University as an example [J]. Scientific and technological bulletin, 2015, $31(02): 247-251$.

[3] Zhong Zhenguo and Zhong Shouman. The training status, problems and countermeasures of full-time master of education professional degree graduate students - taking H Normal University in Zhejiang Province as an example. [J] Journal of Jiangxi Normal University ( Philosophy and Social Sciences ), 2015,48 (06) : 115 - 122.

[4] Xue Yanxu.Focusing on ' four highlights ' to continuously improve the quality of military master ' s degree graduate education - - Taking the pilot of military master 's degree graduate education in National Defense University as an example [J].Dgree and graduate education, 2011 (06) : 6-9.

[5] Chang Baoying.Quality Analysis of Postgraduate Dissertations in School of Computer Science, Beijing University of Technology [J].China Electric Power Education, 2008 (18) : 47-49.

[6] Gong Xianwei. Analysis and improvement of the quality of graduate thesis [J]. Modern business industry, 2016,37 (17) : 170-171.

[7] Wang Cong, Deng Hua.Research on teaching quality management based on Six Sigma [J].Journal of Southeast University ( Philosophy and Social Sciences Edition ), 2015,17 (S1) : 171-173.

[8] Gao Yao, Yang Jiale. Typical problems in ' Problems ' professional master ' s degree papers - Based on the analysis of peer expert text review opinions in Y city paper sampling [J]. Educational science, 2017,33 (03) : 66-71.

[9] Li Zhanhua, Luo Yingzi, Dong Weichun.Quality analysis and countermeasures of master degree thesis of agricultural extension [J].Research on higher education of science and technology, 2006 (06) : 55-56.

[10] Xinyi, Huang Yanmin.Procedure and elements of quality control of the opening report [J].China Higher Education Research, 2010 (05) : 30-32.

[11] Li Anping. Investigation and analysis on the quality of postgraduate dissertations in local universities — taking a university as an example. [J] Contemporary educational science, $2008(15): 17-18+22$.

[12] To establish first-class goals and strengthen connotation construction to promote the high-quality development of degree and graduate education in Jiangsu [J].Dgree and graduate education, 2018 (05) : 1-6.

[13]Deng Yan, Wu Meng. Research on Quality Assurance System for Joint Training of Full-time Master of Engineering [J]. Heilongjiang Higher Education Research, 2014 (10) : 134-136. 